\title{
Color Stability of Two Types of Dental Resin Cements and its Effect on the Color Change of the Ceramic Laminate Veneer with Two Different Thicknesses
}

\author{
Dalia M. El-Bahie', Rania el-sazdy², Amr A. Shebl', Ahmed N. Habib³ \\ ${ }^{1}$ Department of Dental Material, Faculty of Dentistry, Suez Canal University, ${ }^{2}$ Department of Bio Material, \\ Faculty of Oral and Dental Medicine, Cairo University. ${ }^{3}$ Department of Crown and Bridge Department, Fac- \\ ulty of Dentistry, Suez Canal University.
}

\begin{abstract}
Aim: This study aimed to measure the effect of color stability of tested adhesive resin cements on the final color of cemented ceramic veneers, as well as the effect of different thicknesses of ceramic veneers on their final colors. Materials and Methods: A total of twenty-four disc-shaped resin cement specimens were prepared $\{12$ disks/type of cement; the

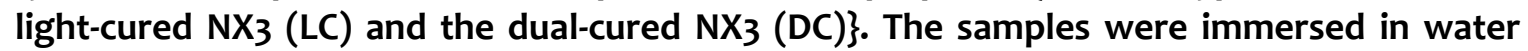
and coffee solutions for 7, 14 days. Forty-eight rectangular-shaped laminate veneers samples were cut from IPS e.max CAD ceramic blocks (24 samples of $0.4 \mathrm{~mm}$ thickness and 24 samples of $0.6 \mathrm{~mm}$ thickness; where 12 samples of each thickness were cemented by light cured resin cement (NX3), and the other 12 samples were cemented by dual cured resin cement (NX3); 6 out of 12 samples were either immersed in coffee solution or immersed in water. The samples were cemented on a Delrin background material. All the samples were examined by a spectrophotometer (VITA Easy shade) before and after immersion in the solutions. Results: The $\Delta \mathrm{E}$ values of dual-cured resin cement disks were higher than those of light cured types. Also, differences were found in $\Delta E$ of the final shade of ceramic veneer when cemented by light cured and dual cured resin cements. Furthermore, there were differences in $\Delta E$ of the final shade when using different ceramic laminate veneers thicknesses. Conclusions: The $\Delta \mathrm{E}$ of the final shade of ceramic veneer was affected by the type of the resin cement used as well as the thickness of ceramic laminate veneer.
\end{abstract}

Keywords: Dual-cured, light-cured resin, coffee solution

\section{Introduction}

In a search for more durable conservative esthetics, porcelain veneers have been introduced during the last decade. Especially, glazed porcelain veneers were proposed as durable anterior restorations with superior esthetics ${ }^{(1)}$. Esthetics of dental veneers is among significant factors affecting the success of such restorations. Although color may play a less important role in clinical success of dental restorations, its psychological esthetic impact may itself. play a decisive role in an overall acceptance by the patient ${ }^{(1)}$. Therefore, color is one of the most important determinants of esthetics(2). The shade of

*Correspondent Author: daliaelbahie@hotmail.com 
ceramic laminate veneer restoration is clinically not only determined by the color of ceramic itself, but also by several other factors including the ceramic thickness, along with the color stability of the luting cement which may affect its long term esthetic (3).

\section{Materials and Methods}

Specimen preparation of resin cement disks: A total of twenty-four disc-shaped resin cement specimens were prepared. These were divided into twelve disks ( $1 \pm$ $0.2 \mathrm{~mm}$ thick, $15 \pm 0.2 \mathrm{~mm}$ diameter) from each type of cement; the lightcured $\mathrm{NX}_{3}$ (LC) and the dual-cured $\mathrm{NX}_{3}$ (DC) (Figure 1).

Specimen preparation of cemented ceramic laminate veneers: IPS e.max CAD ceramic blocks were cut with a microsaw into forty-eight rectangularshaped laminate veneers $(18 \mathrm{~mm}$ width $\mathrm{x}$ $16 \mathrm{~mm}$ height). Twenty-four of the samples were sliced into $0.4 \mathrm{~mm}$ thickness and the other twenty-four samples were sliced into $0.6 \mathrm{~mm}$ thickness. All samples were fired at $850^{\circ} \mathrm{C}$ to complete the crystallization process of the partiallycrystalized glass ceramic. Afterwards, the samples' external surfaces were glazed (IPS e.max glaze, Ivoclar Vivadent) to obtain a smooth surface (Figure $2)$. The inner surface of the ceramic ve- neer was etched with hydrofluoric acid (HF 5\%) for $20 \mathrm{~s}$. Then, the silane coupling agent was applied to the etched surface. White-colored, durable and color stable Delrin material (Acetal polyoxymethylene) was chosen as a bakground material (disks of $3 \mathrm{~mm}$ thickness and $20 \mathrm{~mm}$ diameter). A specially constructed split teflon mold was constructed to ensure cement thickness of $0.1 \mathrm{~mm}$ for all specimens (Figure 3). During sample preparation, background disks were first inserted into the teflon molds, and the Optibond Solo Plus bonding agent was applied to the background material following manufacturer's instructions. The resin cements were either directly applied from the syringe (LC) or were mixed according to the manufacturer's instructions on a separate mixing pad (DC), and applied into the mold over a Delrin background disk using a plastic instrument. Afterwards, the ceramic veneer was inserted into the mold above the resin cement, to be covered with a glass slab. A load of $0.75 \mathrm{~kg}$ was applied for $30 \mathrm{~s}$ on the upper glass slab surface, maintaining a tight contact to the cement, to assure even spread of the cement. After curing the samples, they were removed by dismantling the mold, to immerse them in the planned storage media, namely coffee and water solutions for a period of 7, 14 days (Figure 4)
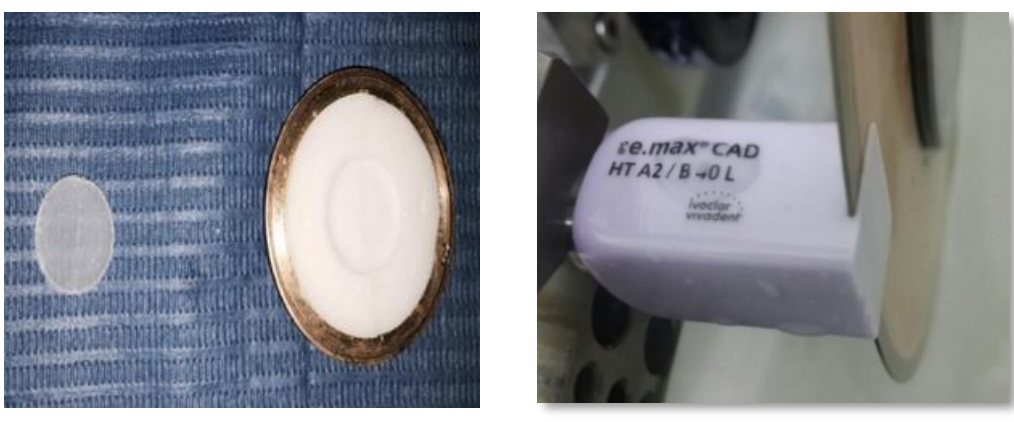

Fig.1: The final cured resin cement specimen
Fig.2: Slicing of E-Max CAD block

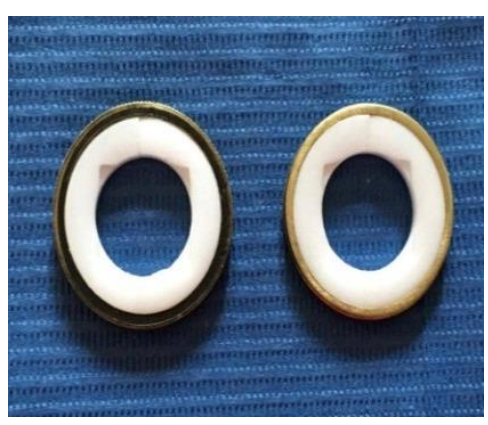

Fig.3: Molds for preparing cemented ceramic veneers samples 

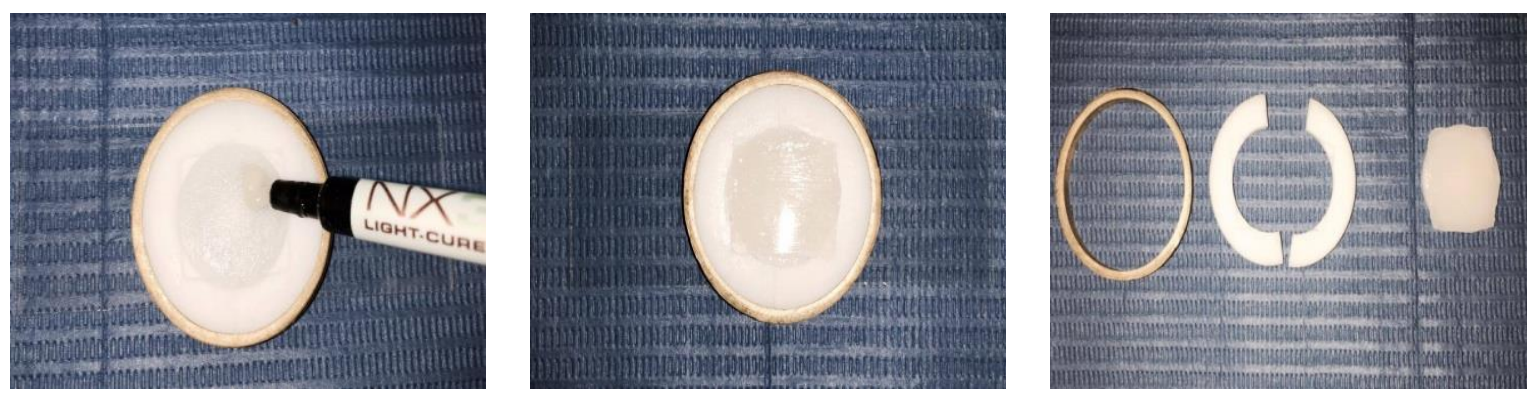

A

B

C

Fig. 4: (a) Resin cement applied over the Delrin background material, b) The Ceramic sample seated over the resin cement, (c) Specimen removal by dismantling the mold.

Color change test measurements:

Color evaluation was performed using a color spectrophotometer (Vita Easyshade; United States). Color measurement for the specimens was performed before immersion in the solutions, and after 7 and 14 days storage period. The color difference $(\Delta \mathrm{E})$ was measured by calculating the color difference of each specimen before and after immersion in the solutions according to the following equation ${ }^{(4)}$ : $\left.(\Delta E)=\left[\left(1 *_{1}-l *_{2}\right)^{2}+\left(a *_{1}-a *_{2}\right)^{2}+\left(b *_{1}-b *_{2}\right)^{2}\right)\right]^{1 / 2}$. $(\Delta E)$ was calculated based on the CIE $L^{*} a^{*} b^{*}$ system, where $L^{*}$ represents to the brightness, $a^{*}$ for redness to greenness, and $b$ * for yellowness to blueness. The subscripts 1 and 2 repre- sent the color coordinates prior and after immersion, respectively. The results were tabulated and statistically analyzed.

\section{Results}

Color change of resin cements disks $(\Delta E)$ : After immersion in coffee solution, dual-cured resin disks showed significantly higher mean $\Delta \mathrm{E}$ values compared to those of light-cured types for both one and two week periods. However, there were no significant difference in $\Delta \mathrm{E}$ values for both types of resin disks after immersion in water for both one and two weeks immersion periods (table 1).

Table 1: Mean and SD of $\Delta E$ for different cements

\begin{tabular}{|c|c|c|c|c|c|c|c|}
\hline & & & \multicolumn{4}{|c|}{ Cement } & \multirow{3}{*}{$\mathrm{p}$-value } \\
\hline & & & \multicolumn{2}{|c|}{ Light cured } & \multicolumn{2}{|c|}{ Dual cured } & \\
\hline & & & Mean & SD & Mean & SD & \\
\hline \multirow[t]{6}{*}{$\Delta \mathrm{E}$} & \multirow[t]{2}{*}{ Water } & 1 Week & 1.69 & 0.64 & 1.72 & 1.00 & 0.955 \\
\hline & & 2 Weeks & 2.44 & 0.84 & 3.09 & 1.09 & 0.281 \\
\hline & \multirow[t]{2}{*}{ Coffee } & 1 Week & 16.84 & 2.73 & 28.36 & 1.78 & $\leq 0.001 *$ \\
\hline & & 2 Weeks & 24.13 & 4.33 & 36.68 & 1.90 & $\leq 0.001 *$ \\
\hline & \multirow{2}{*}{ p-value } & 1 week & \multicolumn{2}{|c|}{$\leq 0.001^{*}$} & \multicolumn{2}{|c|}{$\leq 0.001^{*}$} & \\
\hline & & 2 weeks & \multicolumn{2}{|c|}{$\leq 0.001^{*}$} & \multicolumn{2}{|c|}{$\leq 0.001 *$} & \\
\hline
\end{tabular}

$*=$ Significant at $p$ value $\leq 0.05$

Color change of the cemented laminate veneers: The mean $\Delta \mathrm{E}$ values of the ceramic veneers cemented with dual- cured resin cements were higher than those cemented with light-cured types, except for the group LC.4W1 
which revealed higher $\Delta \mathrm{E}$ values compared to those of DC.4W1 (table 2). The use of different cements significantly affected $\Delta \mathrm{E}$ values of the (DC.6W1, DC.6W2, DC.6C'2) which were significantly higher compared to the groups: (LC.6W1, LC.6W2, LC.6C'2 respectively).

Effect of different ceramic thicknesses of the cemented laminate veneers on $\Delta \mathrm{E}$ : The mean $\Delta \mathrm{E}$ of the $.4 \mathrm{~mm}$ ceramic veneer thickness of the cemented laminate veneers samples showed higher values than those of the higher ceramic thickness $.6 \mathrm{~mm}$, except for the group LC.6C' 1 which revealed higher $\Delta \mathrm{E}$ values compared to those of LC. $4 C^{\prime}$ '1. Different ceramic thicknesses significantly affected mean $\Delta \mathrm{E}$ values. A .4mm thick ceramic showed higher color changes compared to $.6 \mathrm{~mm}$ thick ceramic for the groups: (LC.4W1; LC.6W1), (LC.4C'2; LC.6C'2), (DC.4W1; DC.6W1), (DC.4W2; DC.6W2), and (DC.4C'2; DC.6C'2) (Table 3).

Table 2: Mean and SD of $\Delta \mathrm{E}$ of laminate veneers cemented with different cements

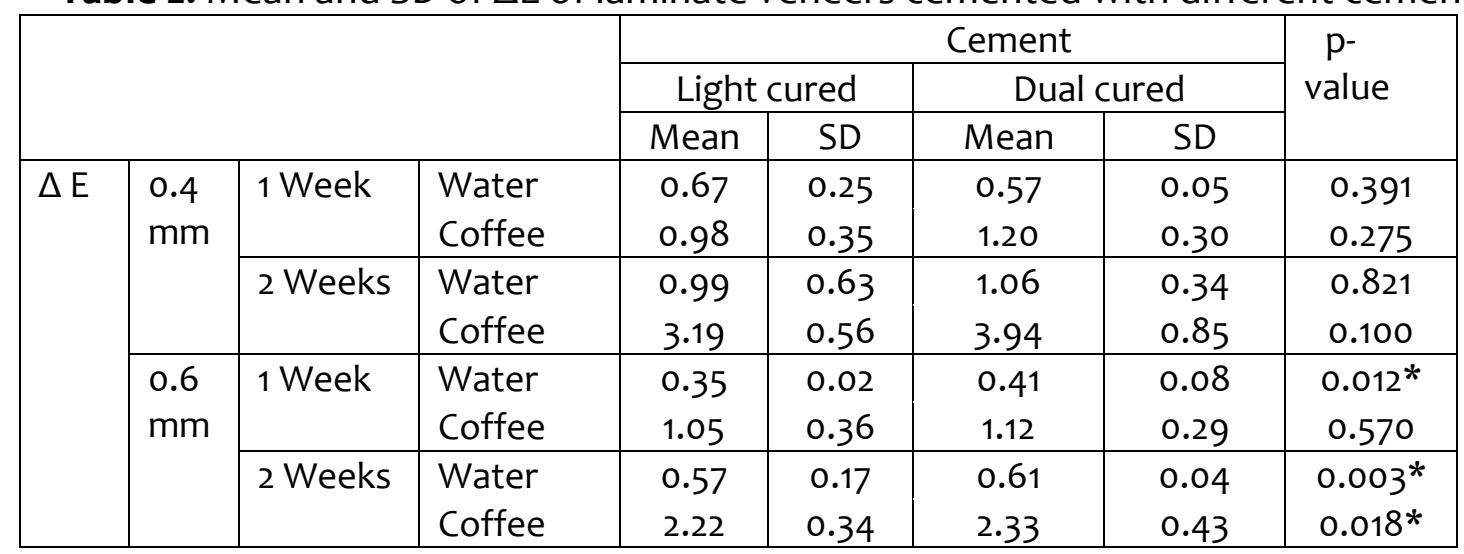

$*=$ Significant at $p$ value $\leq 0.05$.

Table 3: Mean and SD of $\Delta \mathrm{E}$ for different ceramic thicknesses of the cemented laminate veneers.

\begin{tabular}{|c|c|c|c|c|c|c|c|c|}
\hline & & & & & & ckness & & \multirow{3}{*}{ p-value } \\
\hline & & & & \multicolumn{2}{|c|}{$0.4 \mathrm{~mm}$} & \multicolumn{2}{|c|}{$0.6 \mathrm{~mm}$} & \\
\hline & & & & Mean & SD & Mean & SD & \\
\hline \multirow{4}{*}{$\Delta \mathrm{E}$} & \multirow{2}{*}{$\begin{array}{l}\text { Light } \\
\text { cured }\end{array}$} & 1 Week & $\begin{array}{l}\text { Water } \\
\text { Coffee }\end{array}$ & $\begin{array}{l}0.67 \\
0.98 \\
\end{array}$ & $\begin{array}{l}0.25 \\
0.35 \\
\end{array}$ & $\begin{array}{l}0.35 \\
1.05 \\
\end{array}$ & $\begin{array}{l}0.02 \\
0.36 \\
\end{array}$ & $\begin{array}{c}0.043^{*} \\
0.817\end{array}$ \\
\hline & & 2 Weeks & $\begin{array}{l}\text { Water } \\
\text { Coffee }\end{array}$ & $\begin{array}{l}0.99 \\
3.19 \\
\end{array}$ & $\begin{array}{l}0.63 \\
0.56 \\
\end{array}$ & $\begin{array}{l}0.57 \\
2.22 \\
\end{array}$ & $\begin{array}{l}0.17 \\
0.34\end{array}$ & $\begin{array}{c}0.814 \\
\leq 0.001 * \\
\end{array}$ \\
\hline & \multirow{2}{*}{$\begin{array}{l}\text { Dual } \\
\text { cured }\end{array}$} & 1 Week & $\begin{array}{l}\text { Water } \\
\text { Coffee }\end{array}$ & $\begin{array}{l}0.57 \\
1.20\end{array}$ & $\begin{array}{l}0.05 \\
0.30\end{array}$ & $\begin{array}{l}0.41 \\
1.12\end{array}$ & $\begin{array}{l}0.08 \\
0.29\end{array}$ & $\begin{array}{c}0.045^{*} \\
0.169\end{array}$ \\
\hline & & 2 Weeks & $\begin{array}{l}\text { Water } \\
\text { Coffee }\end{array}$ & $\begin{array}{l}1.06 \\
3.94 \\
\end{array}$ & $\begin{array}{l}0.34 \\
0.85 \\
\end{array}$ & $\begin{array}{l}0.61 \\
2.33\end{array}$ & $\begin{array}{l}0.04 \\
0.43 \\
\end{array}$ & $\begin{array}{l}\leq 0.001 * \\
\leq 0.001 *\end{array}$ \\
\hline
\end{tabular}

*=Significant at $p$ value $\leq 0.05$.

\section{Discussion}

Discoloration of adhesive resin cements influences badly the esthetic appearance of ceramic restorations. Marginal discoloration of ceramic ve- neers, inlays and onlays rises with time, owing to the color differences in adhesive resin cements. Consequently, these cements necessitate sufficient color stability in order to maintain good esthetics ${ }^{(6)}$. In general, the $\Delta \mathrm{E}$ of 
the ceramic veneers cemented with dual-cured resin cements showed higher color change than those cemented with light-cured cements. This may be due to the greater $\Delta \mathrm{E}$ color change of the underlying dual-cured resin cement itself, compared to that of the light-cured type. The color difference between both underlying cements may be due to compositional differences between the materials, as well as the method of cement application. As the dual cured resin cement was hand mixed, which leaded to more incorporation of voids and thus inadequate polymerization which made the cement more prone to discoloration compared to the light-cured resin cement which was directly applied as a single paste material into the mold. The thickness of a ceramic can impact the final overall shade of ceramic veneers $(7)$. In the present study, the color change values $(\Delta \mathrm{E})$ obtained for the ceramic veneers cemented by two different resin cements, were higher for the thinner $(0.4 \mathrm{~mm})$ than for the higher $(0.6 \mathrm{~mm})$ ceramic thicknesses for the same cement. This may be due to the fact that thicker ceramics demonstrate less translucency, as they masking the underlying discolored resin cement ${ }^{(8)}$.

\section{Conclusions}

The study concludes that: i) Dual-cured resin cements showed greater color change than light-cured types. ii) Thicker ceramic laminate veneers partially masked the color change of the underlying cement.

\section{References}

1. Paravina RD, Powers JM, Fay RM. Color comparison of two shade guides. Int J Prosthodont. 2002; 15(1):
73-8

2. Omar H, Atta O, El-Mowafy O, Khan Sa. Effect of CAD-CAM porcelain veneers thickness on their cemented color. J Dent 2010; 38(S2): e95-9.

3. Vichi A, Ferrari $M$, Davidson $C L$. Influence of ceramic and cement thickness on the masking of various types of opaque posts. J Prosthet Dent 2000; 83(4): 412-7.

4. Seghi RR, Hewlett ER, Kim J. Visual and instrumental colorimetric assessments of small color differences on translucent dental porcelain. J Dent Res 1989; 68(12): 1760-4.

5. Nakamura T, Saito O, Fuyikawa J, Ishigaki S. Influence of abutment substrate and ceramic thickness on the colour of heat pressed ceramic crowns. J Oral Rehabil 2002; 29(9): 805-9.

6. Santos MJ, Mondelli RF, Navarro MF, Francischone CE, Rubo JH, Santos GC Jr. Clinical evaluation of ceramic inlays and onlays fabricated with two systems: five-year follow-up. Oper Dent 2013; 38(1): 3-11.

7. Wyszecki G, Stiles WS. Color science: Concepts and methods, quantitative data and formulae. 2nd ed. John Wiley 1982.

8. Kilinc E, Antonson Sa, Hardigan PC, Kesercioglu A. Resin cement color stability and its influence on the final shade of all-ceramics. J Dent 2011;. 39(S1): e30-6. 
